\title{
A case study for assessing fish traceability in Egyptian aquafeed formulations using pyrosequencing and metabarcoding
}

\author{
Asmaa Galal-Khallaf a,b, Alaa G.M. Osman ${ }^{\text {c }}$, Carlos E. Carleos ${ }^{\mathrm{d}}$, Eva Garcia-Vazquez ${ }^{\mathrm{a}}$, \\ Yaisel J. Borrell ${ }^{\mathrm{a}, *}$ \\ a Departamento de BiologíaFuncional, Universidad de Oviedo, C/JulianClaveria s/n. 33006 Oviedo, Spain \\ ${ }^{\mathrm{b}}$ Genetic Engineering and Molecular Biology Division, Department of Zoology, Faculty of Science, Menoufia University, Egypt \\ ${ }^{\mathrm{c}}$ Department of Zoology, Faculty of Science, Al-Azhar University, Assiut branch, 71524 Assiut, Egypt

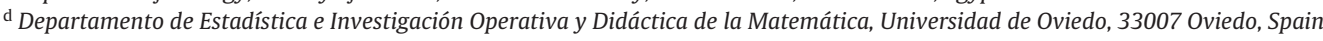

\begin{abstract}
A B S T R A C T
Aquaculture is currently the fastest-growing food production system worldwide. It is highly dependent upon marine capture fisheries as its key dietary inputs, what could seriously compromise oceans biodiversity. Here we employed a DNA metabarcoding approach, based on 454 Next generation sequencing (NGS), for fish species detection in seven Egyptian aqua-feed samples. Up to 13 fish species belonging to four orders (Clupeiformes, Perciformes, Aulopiformes and Siluriformes) were uniquely identified. Saurida undosquamis, Sardinella jussieu, Pangasianodon hypophthalmus and Chelidonichthys kumu were detected as major components. DNA metabarcoding revealed slight differences in the compositions among aquafeeds presented for herbivorous or omnivorous fish. More important, approximately $46 \%$ of all fish species detected are either overexploited or suffering strong decline. These results suggest that more endeavors are necessary for precise fisheries management and biodiversity protection. Although further studies are needed, NGS approaches may provide an effective tool that could help in the implementation of traceability systems for the seafood industry.
\end{abstract}

\section{Introduction}

Aquaculture is the controlled process of farming fish and other aquatic organisms, mainly for food. Due to the intensive demand for seafood products worldwide, aquaculture became the most efficient and rapidly expanding food-producing industry, with expectations for further growth. Global aquaculture is expanding dramatically, reaching 70.5 million tons in 2013 (FAO, 2014). It will exceed the production of beef, pork or poultry in the next decades (FAO, 2012). On the positive side, aquaculture can help biodiversity by reducing pressure on wild fish stocks and allowing partial recovery (Diana, 2009). However, the aquaculture sector is still highly dependent upon marine capture fisheries for sourcing key dietary nutrient inputs, including fishmeal.

Fishmeal is a commercial product made from both the whole fishes and their bones and offal from processed fish in order to provide the farmed fish species with natural high quality proteins. The fishmeal industry relies greatly on a "hunting-and-gathering"

\footnotetext{
* Corresponding author. Fax: +34 985103534

E-mail address: borrellyaisel@uniovi.es (Y.J. Borrell).
}

technique. Cooking, pressing, drying and grinding the fish make fishmeal. As a result, about one-fourth of the seafood harvested from the wild is consumed in fishmeal or other products, not for human consumption (FAO, 2007; Diana, 2009). It seems to be a global trend to produce fishmeal using fish processing waste; for example, in Spain and in United Kingdom accounted for 100 and $84 \%$ of total fishmeal production respectively (Tacon, 2004; Tacon et al., 2006). Currently about $25 \%$ of the world's fishmeal is generated from fish processing wastes (Jackson, 2012). The proportion is expected to increase, given the growth of aquaculture. Furthermore, other fishery products, including mixed tropical trawl fisheries (Jackson, 2012) and small sergestid shrimps and squids are also used in fish meal production. Despite the high demand on "trash fish" (e.g., anchovy, pilchards, herring, sardines, mackerel, capelin, sand eel, menhaden, lizard fish, pony fish) for human consumption in some developing countries (Tacon et al., 2006), it is commonly utilized as fishmeal ingredients for aquaculture. The fishmeal is mainly derived from the reduction of whole small pelagic fish/trash fish to a concentrated high protein form for most fish and animal farms (Huntington and Hasan, 2009). As a consequence, the rapid expansion of aquaculture may be constrained in the future by the dependence on low value/trash fish. Thereby, 
aquaculture can thrive more quickly but negatively, affecting capture fisheries by reducing wild fish inputs.

Therefore, it is clearly important to reveal whether the fisheries involved in fish feed production are sustainable or not. This can be done by the precise detection of all fish species used in the Aquafeed industry. Currently, the majority of global fishmeal production (82\%) does not include in their labels enough details about species compositions (Tacon, 2004). This makes really difficult the problem of evaluating aquaculture and its practices as environmentally responsible. The use of marine resources in an environmentally efficient and responsible manner must include the traceability and transparency of the materials in use.

Despite the crisis of water deficiency, Egypt is still the largest aquaculture producer in Africa. Like many other countries, fish and fishery products play an important role in the Egypt's food security and domestic economy. The Egyptian fisheries resources, which are mainly in the Mediterranean and the Red seas, comprised only $17.26 \%$ of total fish production (Feidi, 2003). Aquaculture represents the largest source of fish supply, showing a significant and rapid growth over the last few years. Consequently, farmed fish production arose from 139,389 tons in 1998 to $1,017,738$ in 2012, counting $74 \%$ of total fish production (FAO, 2013; General Authority for Fish Resources Development (GAFRD, 2013). Currently, Egypt is ranked the 12th largest aquaculture-producing country in the world (El-Sayed, 2007). A Large proportion of Aquafeed ingredients used in Egyptian aquaculture, including fishmeal, is imported (El-Sayed, 2007, 2014). Until now, no clear estimate is available about the animal species (including fish) employed in the imported fishmeal used in Egyptian aquaculture. This aspect, plus the non-compliance of the Egyptian aquaculture system with the EU requirements set out in directive 96/23/EC, have made Egypt not able to meet European union (EU) conditions for the export of products from aquaculture (Goulding and Kamel, 2013).

A variety of DNA-based identification approaches are being extensively used to detect animal species in fishmeal. This includes PCR-sequencing, real-time PCR and PCR-cloning (Krcmar and Rencova, 2005; Ong et al., 2007; Martín et al., 2010; Doosti et al., 2011; Ardura et al., 2012). Recently, next generation sequencing (NGS) techniques have produced a real advancement of genomic methods, allowing the establishment of DNA metabarcoding as a reliable and powerful option for animal species identification (Ficetola et al., 2008; Bott et al., 2010; Taberlet et al., 2012; Thomsen et al., 2012; Pawlowski et al., 2014; Rees et al., 2014; Ardura et al., 2015; Zaiko et al., 2015a,b). There are several platforms available for NGS including Ion Torrent's PGM, Roche/454 Life Sciences, Illumina MiSeq and Pacific Biosciences' RS (Quail et al., 2012; Pochon et al., 2013; Frey et al., 2014; Salipante et al., 2014). The Roche/454 pyrosequencing technique is based on the real time detection of pyrophosphate (PPi) molecules released during the incorporation of nucleotides by DNA polymerase (Ronaghi, 2001). Pyrosequencing technology can be applied for species identification using mini-barcodes that have diagnostic variation between species in conjunction with sequences databases as GenBank or BOLD (Barcoding of Life Data System) (Hajibabaei et al., 2006; Hellberg and Morrisey 2011; Frey et al., 2014; Pochon et al., 2013; De Battisti et al., 2014). As far as we know, no previous attempts were carriedout using this methodology for assessing species composition in fish feeds used for aquaculture.

More than 30,000 fish species are known until now, with extraordinarily interesting and outstanding features in terms of molecular genetics and genome research (Roest Crollius and Weissenbach 2005; Betancur-R et al., 2013). Genetic databases, where metabarcoding procedures are finally directed for the species identification steps, are slightly more complete and/or better curated for fish than for invertebrates species or other vertebrates such as birds, despite still being poor in species coverage
(Kwong et al., 2012). The main purpose of this study was to use a DNA metabarcoding approach, applying the Roche/454 platform, for disclosure of fish species in the fish feeds used for Egyptian aquaculture as a case study. Also, we aimed to evaluate the overall sustainability, or environmental "safety", of these fish feed products taking into account the current state of the related fisheries. To achieve our goals, we employed the sequencing of a short fragment of mitochondrial cytochrome oxidase subunit I(COI) (130 bp), that has been successfully used for species-level identification in several animal groups worldwide (Hebert et al., 2003; Hajibabaei et al., 2006; Meusnier et al., 2008; Ardura et al., 2015; Zaiko et al., 2015a,b). We expected by this study to provide a new, molecular based tool that can help Egyptian and international authorities to achieve, or develop a more sustainable and responsible controlling systems for aquaculture.

\section{Material and methods}

\subsection{Fish feed samples}

In the current study, a number of visits on seven different feed mills were carried out in the cities Alexandria, Kafr el sheikh and Edku in the North of Egypt during the period from February to April 2014, considering the concentration of most Egyptian aquaculture activity in those cities. Seven different fish feed samples (FM 1-7) were collected from these feed mills. Five of them (brands FM2, FM3, FM4, FM6 and FM7) are incorporated in aquaculture for feeding herbivorous (the Tilapia Oreochromis spp. and the Common Carp Cyprinus carpio) and omnivorous species (the Flathead Grey Mullet Mugil cephalus and the Thinlip Mullet Liza ramado). Additional two samples (brands FM1 and FM5) are employed to feed carnivorous fishes (the Gilthead Sea Bream Sparus aurata, the Mediterranean Meagre Argyrosomus regius and European Sea Bass Dicentrarchus labrax) (Table 1). However, all packs were found labeled only with "fish powder" (fishmeal) with no reference to particular species. Additional miscellaneous ingredients such as soya beans, rice, corn, lentils and oil were also displayed on the labels. After collection, the fish feed samples were express posted to the laboratory of Natural Resources of the Department of Functional Biology, Oviedo University, Spain for further analysis.

\subsection{DNA isolation from fish feeds}

It is well known that fat and oil that exist in the fishmeal may interfere with the DNA extraction. So, for assuring successful DNA extraction process, it was necessary to remove these components. The removal process was performed using the following procedure: resuspending the meals in a solution of methanol-chloroform-water $(2: 1: 0.8)$ for $2 \mathrm{~h}$, then washing in distilled water, and finally rinsing with Phosphate buffered saline (PBS) $1 \times$ buffer to eliminate the any remnant that may exist (Ardura et al., 2012). Total genomic DNA of five replicates of each sample was extracted using QIAamp ${ }^{\circledR}$ DNA Mini Kit (Qiagen, Germany) following manufacturer's instructions. DNA extraction was conducted in sterility measures, inside laminar air flow chamber continuously disinfected by UV light and absolute ethanol cleanings to prevent contaminations. DNA extractions were made in an exclusive sterile room in an external, and different, building. All DNA obtained from replicates of the same sample was pooled in one eppendorf tube. DNA samples were concentrated using Speed vac instrument and screened in agarose gels. Working aliquots of DNA were stored at $4{ }^{\circ} \mathrm{C}$ for analysis, and the rest was frozen at $-20^{\circ} \mathrm{C}$ for archival storage. All the samples passed a quality check (QC) where quantity (Picogreen method using Victor 3 fluorometry), purity (NanoDrop instrument), DNA integrity (Gel 
Table 1

Label information of all samples including the fish feed composition and the collecting cites and the farmed fishes they are used to feed.

\begin{tabular}{|c|c|c|c|}
\hline Fish feed & Aquaculture fishes & Ingredients & Sampling location \\
\hline FM1 & $\begin{array}{l}\text { Carnivorous fishes: Gilthead Sea Bream and European Sea } \\
\text { Bass }\end{array}$ & $\begin{array}{l}\text { Fish powder, soya } \\
\text { beans, corn, rice and oil }\end{array}$ & Alexandria \\
\hline FM2 & $\begin{array}{l}\text { Herbivorous and omnivorous fishes: Blue Tilapia, Redbelly } \\
\text { Tilapia, Nile Tilapia, Mugil and Thinlip Mullet }\end{array}$ & & Idku \\
\hline FM3 & $\begin{array}{l}\text { Herbivorous and omnivorous fishes: Tilapia, Mugil, Thinlip } \\
\text { Mullet }\end{array}$ & & Idku \\
\hline FM4 & $\begin{array}{l}\text { Herbivorous and omnivorous fishes: Tilapia, Mugil, Thinlip } \\
\text { Mullet and Common Carp }\end{array}$ & Fish powder, soya beans, lentils, rice and oil & Kafr el sheikh \\
\hline FM5 & $\begin{array}{l}\text { Carnivorous fishes: Gilthead Sea Bream and Mediterranean } \\
\text { Meagre }\end{array}$ & Fish powder, meat powder, soya beans, rice and oil & Alexandria \\
\hline FM6 & $\begin{array}{l}\text { Herbivorous and omnivorous fishes: Tilapia, Mugil and } \\
\text { Thinlip Mullet }\end{array}$ & soya beans, lentils, rice and corn & Kafr el sheikh \\
\hline FM7 & $\begin{array}{l}\text { Herbivorous and omnivorous fishes: Tilapia, Mugil and } \\
\text { Thinlip Mullet }\end{array}$ & Fish powder, soya beans, corn and oil & Alexandria \\
\hline
\end{tabular}

electrophoresis method) and sizes (Bioanalyzer) were assessed. Total genomic DNA was successfully extracted from all samples with a good quality (A 260/A 280), ranging between 1.6 and 1.9 and concentrations between 10.5 and $94.8 \mathrm{ng} / \mu \mathrm{L}$.

\subsection{Preliminary in silico analysis of Universal mini-barcoding primer pairs}

Fish from 17 different families and 5 orders (Scorpaeniformes, Siluriformes, Perciformes, Clupiformes and Aulopiformes) were targeted for a preliminary in silico analysis taken into account the availability of referenced COI sequences for these species in genetic databases. The fish species used are listed in Annex 1. In total, $85 \mathrm{COI}$ sequences from different fish species were retrieved from GenBank (http://www.ncbi.nlm.nih.gov/) and BOLD (http:// boldsystems.org/) databases. Barcodes of $652 \mathrm{bp}$ were aligned using the ClustalW application included in the Mega 6 software (Tamura et al., 2013). A region of $124 \mathrm{bp}$, the region flanked by the primers UniMinibarFw and UniMinibarRv (Meusnier et al., 2008), was used to check the ability of this minibarcode to discriminate between fish species. The MEGA 6 program (Tamura et al., 2013) was also employed for calculating pairwise distances (Annex 1) and for constructing a phylogenetic tree using Maximum likelihood method based on Kimura 2-Parameter $(\mathrm{K} 2+\mathrm{G}+\mathrm{I})$ model and 1000 bootstrap replicates (Annex 2).

Supplementry material related to this article found, in the online version, at http://dx.doi.org/10.1016/j.fishres.2015.09.009.

Supplementry material related to this article found, in the online version, at http://dx.doi.org/10.1016/j.fishres.2015.09.009.

\subsection{Polymerase chain reaction (PCR), massive sequencing and bioinformatic analyses}

Universal mini-barcoding primer pairs coupled with barcode sequences and the key tracts used for massive sequencing in Roche/454 platform were used for PCR amplification of a short fragment of the mitochondrial COI gene as recommended for degraded DNA: Uni MinibarF1: 5'-TCCACTAATCACAARGATATTGGTAC-3' and Uni-MinibarR1: 5'-GAAAATCATAATGAAGGCATGAGC-3' (Meusnier et al., 2008). PCR reactions were undertaken by Macrogen Korea based on the original protocol described by Meusnier et al. (2008) using blank amplifications for avoiding possible contaminations. Library constructions included control steps for sizes (Agilent Technologies 2100 Bioanalyzer using a DNA 1000 chip) and quantity (Roche's Rapid library standard Quantification solution and calculator). The bands of expected size ( $\approx 150-200 \mathrm{bp})$ were sequenced with Roche's 454 pyrosequencing technology. The next task was to assign the multiplexed reads to samples based on their nucleotide barcode (demultiplexing). The software uses barcode sequences to segregate the reads from each sample, by matching the initial and final bases of the reads to the known tag sequences used in the preparation of the libraries. Zero base errors were allowed in this sorting by tag step. This step also performs quality filtering based on the characteristics of each sequence, removing any low quality or ambiguous reads.

Quality control and filtering of the resulting reads (fasta and .qual files by samples) were afforded using PRINSEQ v0.20.4 (Schmieder and Edwards, 2011) and QIIME softwares (Caporaso et al., 2010). Sequences that failed to meet the criteria of length greater than $100 \mathrm{bp}$ and a mean quality score $\geq 20$ measured as Phred scores and revealing potential chimeric sequences (detected using the blast fragment approach in QIIME) were removed. QIIME was also used for a Cytochrome Oxidase I (COI)-focused metabarcoding analysis. A reference taxonomical database was created by downloading all available mitochondrial Cytochrome Oxidase I sequences from the NCBI taxonomy databases (taxdump.tar.gz and gi_taxid_nucl.dmp.gz). This was done by searching the "mitochondrial COI" in the NCBI website and downloading a total of 911,594 sequences available until December 2014 in a .fasta formatted file. The next step was the execution of a script called entrez_qiime.py. This python script was created by Baker (2014) and it takes as inputs the .dmp files that associate de NCBI's gene identifier number with its corresponding taxon identifier number generating the mitochondrial_COI_stripped.fasta, mitochondrial_COI_taxid_taxonomy.txt, mitochondrial_COI_gi.txt, mitochondrial_COI_gi_taxonomy.txt and mitochondrial_COI_gi_taxid.txt files. These files were used as our reference taxonomical database. For the OTUs identifications, the QIIME protocol(qiime.org/ tutorials/tutorial.html) "de novo OTU picking and diversity analyses using 454 data"was adopted.

We assigned taxonomy through a BLAST search against our reference gene database using $90 \%$ identity and $E$-value threshold of 0.001 as cutoffs (QIIME procedures and protocol). Approximately, 8000 raw reads were obtained per sample after data processing. Thereafter, the sequences were clustered into operational taxonomic units (OTUs) with their consensus lineage and considered just in those cases in which more than 10 sequences by OTU appeared. A second approach was used for confirming our fish species assignations after BLAST; that was the construction of phylogenetic tree using the Maximum likelihood method based on on Kimura 2-Parameter $(\mathrm{K} 2+\mathrm{G}+\mathrm{I})$ model and using 50-100 randomly selected NGS sequences of the alleged species. The detected haplotypes were aligned with reference sequences (one by species) retrieved from Genbank database (Accession numbers: HQ945857.1, KJ709498.1, KF604671.1, JF494684.1, EF609413.1, KJ202212.1, HQ231362.1, EU595257.1, KC015291.1, KJ205205.1, JF952847.1, KC501292.1 and HM180639.1) and Bootstrap analysis was performed (1000 replicates). 


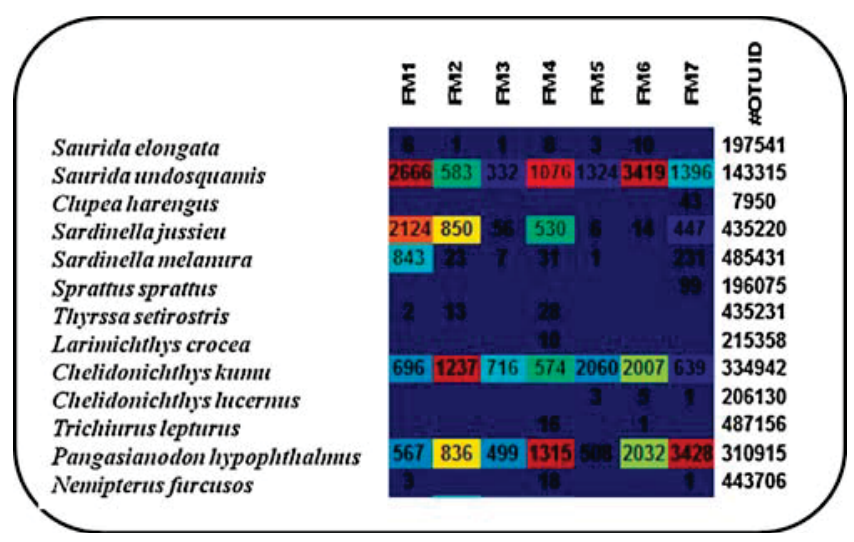

Fig. 1. The OTU heatmap displaying the OTU counts per sample. (Blue: contributes low percentage of OTUs to sample; red: contributes high percentage of OTUs). (For interpretation of the references to colour in this figure legend, the reader is referred to the web version of this article.)

\section{Results}

All the seven fish feed products under study exhibited nonspecific labeling with no species or even genus details on their labels (Table 1). This means that all of them cannot be traced for responsible or sustainable practices. Thus, DNA methodologies that could work in processed and degraded samples are necessary for affording traceability studies. The massive sequencing of the short PCR products (the 5 '-extremity of the COI gene) obtained from the samples libraries, resulted in a total of 116,038 raw reads, $22,157,548$ bases and an average read length of $190 \mathrm{bps}$. After the sorting and demultiplexing steps, these figures were reduced to 106,485 reads, $16,560,973$ bases and 155 bps as average mean length. The denoising process reduced this further, to a total of 65,253 raw reads with a mean of 9321 raw sequences by sample (ranging from 4982 reads in sample FM3 to 14,377 reads in sample FM5). All reads were clustered into operational taxonomic units (OTUs) after the assignment process by classifying the reads at different taxonomic levels (phylum, class, order, family, genus, species) based on the similarities ( $E$ values and identity criteria) of the sequences with those in the reference database. A total of 56,237 hits belonging to several phyla (Arthropoda, Nematoda, Mollusca, Ascomycota, Chordata, Phaeophyceae, Basidiomycota and Streptophyta) were obtained after assignments (mean number of hits by sample $=8033$ ), while for the others 9016 sequences there were no significant matches. A total of 33,345 reads (59\%) were identified as sequences from fish species. After BLAST comparisons, a total of 13 fish species were found inside fish feed samples belonging to four orders, namely: Clupeiformes (38.4\%), Perciformes (38.4\%), Aulopiformes (15.4\%) and Siluriformes (7.7\%) (Fig. 1). The utility of the $5^{\prime}$ terminal region of the COI gene for a reasonable discrimination of fish species was previously confirmed in this work (Annex 1 and 2). Species assignments were re-assessed in this work using a phylogenetic approach for confirming BLAST results. Six families and three orders seem to be clearly differentiated and the NGS haplotypes obtained here for each of the fish species were clustered together with their expected reference sequences at the same branches (Fig. 2). Although two species inside the genera Chelidonichthys and Saurida are certainly phylogenetically related, BLAST species identifications gave 100\% identity in case of Chelidonichthys and $98 \%$ in case of Saurida. Additionally, the pairwise distances among species were $>2 \%$ in all cases.

The seven fish feed samples could be grouped into two sets (groups A and B) according to the type of fish that they are used to feed. Samples FM1 and FM5 (group A) are being produced to feed carnivorous fishes. Slight differences in fish compositions
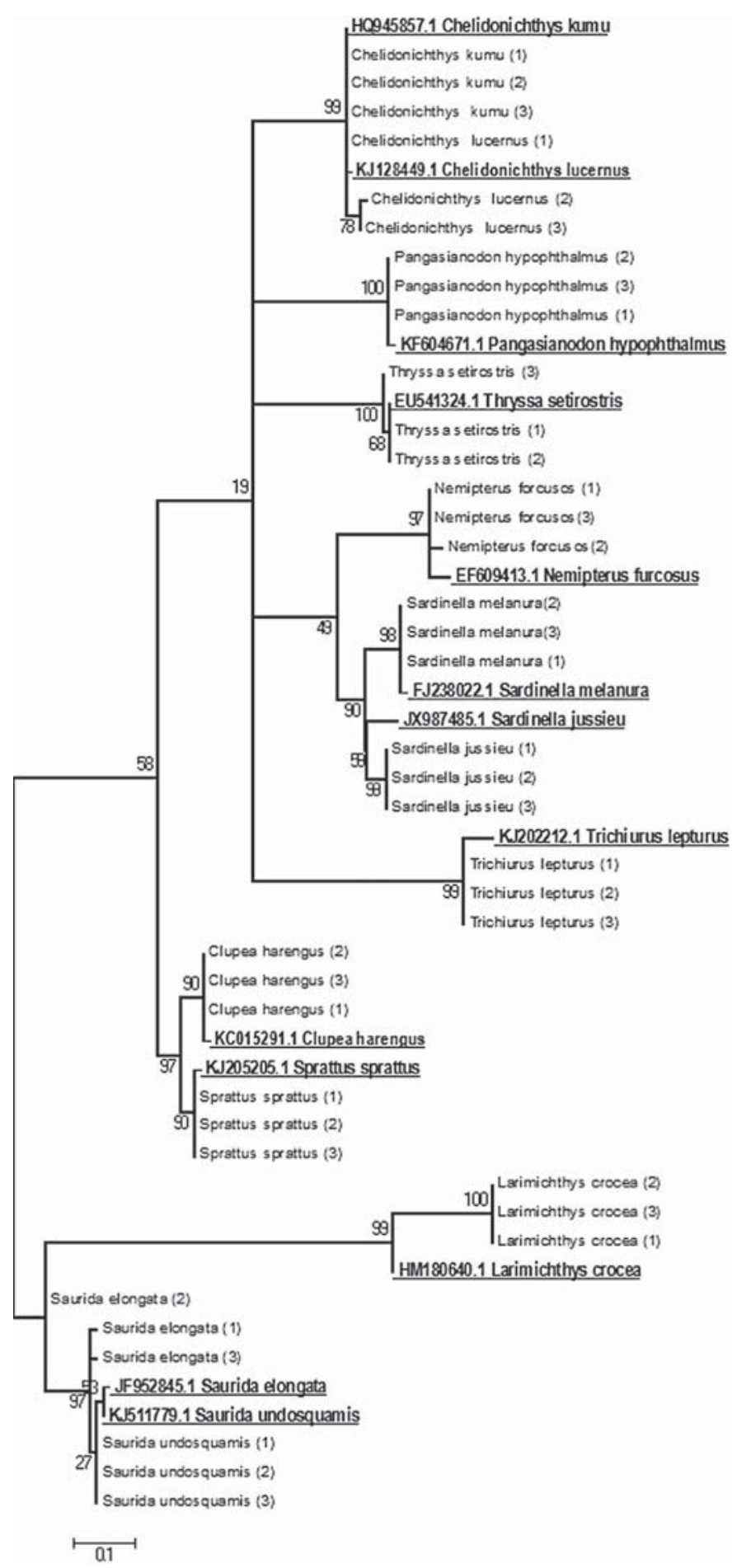

Fig. 2. Maximum Likelihood phylogenetic tree based on the Kimura 2-Parameter model $(\mathrm{K} 2+\mathrm{G}+\mathrm{I})$ using the mini-COI sequences obtained in this study and reference sequences (in bold) retrieved from Genbank database.

were detected for both groups of fish feeds. In sample FM1 the most abundant species found was the Brushtooth Lizardfish (Saurida undosquamis) (38.6\%) followed by the Mauritian Sardinella (Sardinella jussieu) (30.8\%) and the Blacktip Sardinella (Sardinella melanura) (12.2\%) (Fig. 1). Additional non-negligible amounts of the Blue Gurnard (Chelidonichthys kumu), the Iridescent Shark (Pangasianodon hypophthalmus) were also detected (Fig. 1). The Blue Gurnard (C. kumu) and S. undosquamis represented the dominant species in the FM5 product with more than 2000 and 1000 reads, 
Table 2

The geographical origin of all fish species detected in the analyzed fish feeds and its conservation state (In bold species with non-sustainable fisheries).

\begin{tabular}{|c|c|c|c|}
\hline Species detected & Geographical distribution & Conservation state & References \\
\hline Trichiurus lepturus & $\begin{array}{l}\text { Circumtropical and temperate waters of } \\
\text { the world }\end{array}$ & Overexploited & Meriem et al. (2011) \\
\hline Larimichthys crocea & $\begin{array}{l}\text { Northwest Pacific: } \\
\text { Yellow and East China seas }\end{array}$ & Overexploited & Jin-qing et al. (2012) \\
\hline Saurida elongata & $\begin{array}{l}\text { Northwest Pacific: Japan to the } \\
\text { northern South China Sea }\end{array}$ & Overexploited & Jianguo et al. (2011) \\
\hline Saurida undosquamis & Eastern Indian Ocean & Severe overexploitation & Mahmoud et al. (2014) \\
\hline Pangasianodon hypophthalmus & Asia & Endangered & Vidthayanon and Hogan (2013) \\
\hline Sprattus sprattus & $\begin{array}{l}\text { Northeast Atlantic Ocean, northern } \\
\text { Mediterranean and Black Sea }\end{array}$ & Depleted & FAO (2011) \\
\hline Chelidonichthys kumu & Indo-West Pacific & Low to moderate vulnerability & Cheung et al. (2005) \\
\hline Chelidonichthys lucernus & $\begin{array}{l}\text { Eastern Atlantic Ocean, } \\
\text { Mediterranean and Black seas }\end{array}$ & High vulnerability & Cheung et al. (2005) \\
\hline Nemipterus furcosus & Indian Ocean & Low vulnerability & Cheung et al. (2005) \\
\hline Sardinella jussieu & Western Indian Ocean & Low vulnerability & Cheung et al. (2005) \\
\hline Sardinella melanura & Indo-West Pacific Ocean & Low vulnerability & Cheung et al. (2005) \\
\hline Thryssa setirostris & Indo-Pacific Ocean & Low to medium vulnerability & Cheung et al. (2005) \\
\hline Clupea harengus & North Atlantic Ocean & Moderate vulnerability/Least concern & Cheung et al. (2005)/Herdson and Priede (2010) \\
\hline
\end{tabular}

respectively (Fig. 1). There were five samples under study (group B) that are used to feed herbivorous fishes in the Egyptian aquaculture (FM2, FM3, FM4, FM6 and FM7). The species P. hypophthalmus and S. undosquamis were the dominant species in those samples with more than a $66 \%$ of the total components found (Fig. 1 ). Two other fish species, C. kumu, and S. jussieu were also incorporated showing $22.9 \%$ and $8.4 \%$ of abundance values, respectively. Beside this, the Largehead Hairtail (Trichiurus lepturus) appeared for the first time in the FM4 product whereas the Atlantic Herring (Clupea harengus) and the Mediterranean pelagic European sprat (Sprattus sprattus) were detected only in FM7 (Fig. 1). Additional fish species such as $S$. melanura and the tub gurnard (Chelidonichthys lucernus) were also detected in this study (Fig. 1).

An interesting issue related to the current conservation status of fish population stocks was revealed by this work. In details, one species $S$. undosquamis, found in all products analyzed here, although it is suffering overfishing (Table 2). Furthermore, one IUCN endangered species of panga fish (P. hypophthalmus) was also found in all samples. More cases of species found in this work are currently being overexploited or with depleted population. Among these overexploited species were the Slender lizardfish (Saurida elongata), S. sprattus, T. lepturus and the Large yellow croaker (Larimichthys crocea) (Fig. 1; Table 2). These results revealed that all of the seven samples included some kind of unsustainable fisheries and then are not really environmentally safe.

\section{Discussion}

Traceability of pellets used for feeding fish is an innovative aspect for the conservation of fisheries resources. Little published information is available on aquaculture management in Egypt in general, and feed management strategies in particular (El-Sayed, 2007). The description of food, in terms of its composition, is a critical issue that plays an important role in protecting consumers and enforcing the appropriate food regulation laws. Fishmeal is recognized by nutritionists as a high-quality, very digestible feed ingredient that is favored for addition to the diet of most farm animals, especially fish (Miles and Chapman, 2006). It can be made from almost any type of seafood and small marine fish that contains a high percentage of bones and oil, and usually deemed not suitable for direct human consumption. In Egypt, it was estimated that about 28,000 tons of fishmeal are currently used by the Aquafeed industry (El-Sayed, 2014). Traceability of these products is a need for the establishing of a sustainable aquaculture.

A plenty of polymorphic DNA should exist in the food sample to enable accurate species identification and thus traceability.
Several genes exhibit these criteria, but the use of mitochondrial DNA genes is more widespread due to the existence of much more copies of it in a cell (up to 1000 times or more) than the nuclear DNA, and it also shows higher evolution rates and more prominent polymorphic patterns. Its use can help then in the discrimination of species contained in food materials, even if the DNAs of these species are partially degraded or damaged (De Battisti et al., 2014). The main advantage of using minibarcodes is that the target fragment is very short and can be amplified even in degraded DNA from highly processed food. Furthermore, it can be applied in mixed food products that cannot be directly sequenced. A universally short primed amplicon is ideal for sequence characterization through new high throughput sequencing technologies, allowing comprehensive studies of biodiversity to be a realistic goal (Meusnier et al., 2008). In our study, the $5^{\prime}$ terminal region of the COI gene, although short, was informative and proved to be capable of distinguishing among fish species.

Some of the established techniques for assessing the composition of fishmeal have been now disused because of their low specificity and unsuitability for the cases of highly processed food products such as fishmeal (Bottero and Dalmasso, 2011). Cloning of PCR products and subsequent Sanger dideoxy sequencing have been widely used in seafood traceability studies, particularly to look at fishmeal composition, but cloning needs sequencing of many clones and is prone to host-related biases. Moreover is lengthy, and is quite intensive labor for accurate studies (i.e., Ardura et al., 2012). Here we employed a DNA-based technology using a NGS approach with a proven utility for species identification (Bott et al., 2010; Thomsen et al., 2012; Pochon et al., 2013; De Battisti et al., 2014; Ardura et al., 2015; Zaiko et al., 2015a,b). DNA metabarcoding studies are mainly used by molecular ecologists interested in biodiversity assessment of environmental samples such as soil, water or marine sediments (Taberlet et al., 2012; Rees et al., 2014; Goldberg et al., 2015; Ficetola et al., 2015). As all emerging methodologies, DNA Metabarcoding also have some shortcomings (Morozova and Marra 2008; Zaiko et al., 2015a,b; Ficetola et al., 2015). Main problems can be the high costs (Bott et al., 2010), lack or ambiguity of reference sequences in databases that difficult species identification (Kwong et al., 2012; Ardura et al., 2013), lack of adequate primers' specificity (Pochon et al., 2013; Wilcox et al., 2013; Clarke et al., 2014; Deagle et al., 2014) and reliability (Ficetola et al., 2015). All these problems should be taken into account for future enhancements and to make such technologies more wide-spread.

The prices for using high throughput sequencing technologies are still high (i.e., mean of $205 €$ by sample in this study). The cost is slowly going down and it is expected to be more accessible in 
upcoming years. It has been claimed that in cases of high number of samples to be sequenced, the use of the MiSeq platform seems superior to other NGS platforms in terms of throughput and cost efficiency (Quail et al., 2012; Frey et al., 2014; Salipante et al., 2014). In our study, with so few samples, 454 pyrosequencing was costeffective and very useful information was obtained.

Another relevant requisite for metabarcoding analyses is the availability of high quality reference databases (Collins et al., 2012; Kwong et al., 2012; Zaiko et al., 2015b). GenBank database provides a great resource in terms of taxon coverage and extra information, providing sometimes expert-identified, wild-caught specimens with published locality data. However, this does not mean there are not mistakes and taxonomical mismatches that might affect the alignment success and/or increase ambiguity. Moreover, less studied species are not represented (Collins et al., 2012). Bold data seems to be better curated, but also suffers from misidentified specimens to some degree and the user may be able to query a sequence against the full database, but the underlying data remain hidden (Collins et al., 2012; Kwong et al., 2012; Ardura et al., 2013). In our case, we compiled our own reference database using complete GenBank records (sequences without complete taxonomical information are discarded after the entrez_qiime.py procedure). We added identity and coverage (and not only $E$-values as in the megablast procedure at NCBI) as relevant sorting criteria when obtaining blast hits in QC steps and QIIME analyses. Posterior analyses, including in silico work and phylogenetic approaches, were also used to confirm blast assignments, giving them more reasonable accuracy for fish identification purposes. In any case, false positives (Type-I errors) cannot be excluded as a possibility. Quality controls to eliminate ambiguous sequences, homopolymers and possible chimeras (as it was done in this work) help to reduce chances for erroneous species assignments together with improved reference databases. Both aspects need more attention and efforts for the upcoming years in the development of the Metabarcoding methodology (Kwong et al., 2012; Ficetola et al., 2015; Zaiko et al., 2015b).

Primers' specificities, and their use for detecting biodiversity, have been a hot spot and a relevant issue in papers about metabarcoding (Pochon et al., 2013; Wilcox et al., 2013; Clarke et al., 2014; Deagle et al., 2014). It has been claimed that the COI gene is not good enough for this kind of studies (i.e., Deagle et al., 2014). However, it has been very useful in plenty of reports (De Battisti et al., 2014; Frey et al., 2014; Pochon et al., 2013; Ardura et al., 2015; Zaiko et al., 2015a,b). This does not deny the possibility of false negatives (Type-II errors) due to its lacks of universality (Clarke et al., 2014; Deagle et al., 2014). Avoiding Type-II errors could include the combined analyses with different genetic markers for each of the samples in the future (i.e., combining the use of COI and eukaryotal ribosomal genes (Hadziavdic et al., 2014)) and the use of several replicates for samples and for PCRs (Ficetola et al., 2015; Zaiko et al., 2015a,b).

To evolve to a more responsible and sustainable aquaculture seems to be an urgent necessity nowadays. Approximately, 50\% of species/genera detected in the imported fish feeds used for Egyptian aquaculture are either overexploited or suffered from strong decline (Table 2). S. undosquamis represents the essential fish species in all fish feed samples under study. Mahmoud et al., (2014) reported that the S. undosquamis stock in the Egyptian Mediterranean coast is in a state of high overfishing and severe overexploitation, particularly in the Gulf of Suez (El-Halfawy et al., 2007). Moreover, T. lepturus is overexploited in the main fishing area in the Northwest Pacific (Meriem et al., 2011), in the Aru Sea off Indonesia (Cheng et al., 2013) and in Visakhapatnam waters (Reuben et al., 1997). It seems that the stock of $L$. crocea has been over-exploited in Guanjinyang (Jin-qing et al., 2012) and the status of S. sprattus is depleted in the Mediterranean and Black Sea (FAO,
2011). Other cases, including S. elongate that is under heavy overfishing in various parts of the China Sea (Zirong and Zuozhi, 2005) and one IUCN endangered species of panga fish ( $P$. hypophthalmus) (Vidthayanon and Hogan, 2013), have been detected (Table 2). Moreover, all fish feed products under analysis contained species from the by-catch of trash fish fisheries such as $S$. undosquamis (Jianguo et al., 2011) and C. kumu (Acero et al., 2010). On this regard, low-value seafood species, including trash fish, especially members of the orders Clupeiformes and Aulopiformes have been detected in the present work. This finding supported the idea of the continuous use of trash fish in aqua-feed industry, increasing fishing pressure on the already overexploited fish stocks. This could be a consequence of the everlasting expansion of the mariculture industry in Asia. The demand for trash fish/low-value fish has also steadily increased, because carnivorous fish cannot thrive without fish or other marine proteins (Gomez et al., 2010). A significant quantity of trash fish (conservatively estimated as 2.3 million tons per year) is being used by the pet food industry (Hasan and Halwart, 2009). Our results, essentially, revealed that the implementation of traceability systems for the seafood industry are an emergency case since fish feed products are now clearly far from being sustainable or responsible.

Finally, the species found in feeds for herbivorous, omnivorous and carnivorous fish species did not vary a lot, but certain differences were found in terms of percentages of appearances. This could suggest a trend (that must be encouraged) in the Egyptian fish feed formulation companies to differentiate the feed according to the proper feeding habits of the targeted organism. Although fish feed for herbivorous fish must contain a good percentage of animal component for efficient conversion and for enhancing immunity and many other life aspects (Olvera-Novoa et al., 1998), some studies suggested the possibility of partial replacements of fishmeal protein by plant proteins (Thompson et al., 2012; Trosvik et al., 2013). Even China, the major producer of tilapia and carps in the world, uses very low quantity of fishmeal for tilapia (2-5\%) and carps (0-12\%) (Tacon and Metian, 2008). This replacement exhibits several benefits, mainly economic, as it reduces diet cost and allows sustainable production; and ecological, as reducing unnecessary protein supply reduces nitrogenous wastes and contributes much to both aquaculture and environmental heaths. It is well known that ammonia is excreted as the end product of protein catabolism, and may be toxic if allowed to accumulate (Hargreaves, 1998). Ammonia toxicity in aquaculture ponds is manifested by sub-lethal reduction of fish growth or suppression of immune-competence. In Egypt, pond aquacultures for these species (tilapia, carps, and Mugilids) are currently facing massive mortalities; most of them are due to outbreaks of bacterial infections and other reasons (Aly, 2013; personal observations). This can be attributed to the imbalance in protein content that can be detected in fish feeds. We believe that the aquaculture sector will gain more benefits from more studies concerned with a strict balance of fish feed components, and especially for production of more species-specific fish feeds that consider both the economic and the ecological impacts of fish nutrition.

\section{Conclusions}

The use of DNA metabarcoding approaches to study seafood components used in Aqua-feed industry is a very promising, and necessary, research field, although further research efforts are required for its implementation. A total of 13 fish species have been detected in seven Egyptian fish feed samples. Approximately, $46 \%$ of fish species detected in this study, as fish feed components, are either overexploited or suffered from strong decline. In this 
scenario, an aquaculture regulatory framework in the countries concerned with fish feed production and trading, including Egypt, should be established in order to regulate fisheries and aquaculture sustainability and to protect biodiversity. Finally, we strongly recommend the introduction of NGS technologies as a tool for fish feed inspections in order to balance/regulate the fish feed productions for sustaining both animal and human life.

\section{Acknowledgements}

Galal-Khallaf, A. was funded by a PhD fellowship from the MEDASTAR Erasmus Mundus Programme (2013-2015). Authors would like to appreciate their thanks to Mr. Mohammed M. Elfeky (Al-Azhar University, Egypt) and Dr. Khaled Mohammed-Geba (Menoufia University, Egypt) for their help in collecting fishfeeds samples. The authors also thank Drs. Ferran Briansó and Alex Sánchez from the Unitat d'Estadísticai Bioinformática of the Valld'Hebron Institut de Recerca (VHIR) (UEB) for their help in the analysis and Pipeline Development for COI-focused Metabarcoding of samples. This work was funded by University of Oviedo and Asturian government (Spain) and it is a contribution from the Marine Observatory of Asturias (OMA) and the Research Group GRUPIN14-093. The Journal Editor and two anonymous reviewers contributed to the improvement of this paper and they are also acknowledged.

\section{References}

Acero, A., Fricke, R., Murdy, E., 2010. Chelidonichthyskumu, The IUCN Red List of Threatened Species, Version 2014.3. <www.iucnredlist.org>, Downloaded on 06 February 2015.

Aly, S.M., 2013. A Review of Fish Diseases in the Egyptian Aquaculture Sector: Working Report. WorldFish, Penang, Malaysia.

Ardura, A., Horreo, J.L., Hernandez, E., Jardon, A., Pola, I.G., Martinez, J.L., Garcia-Vazquez, E., 2012. Forensic DNA analysis reveals use of high trophic level marine fish in commercial aquaculture fish meals. Fish. Res. 115-116, $115-120$.

Ardura, A., Planes, S., Garcia-Vazquez, E., 2013. Applications of DNA barcoding to fish landings: land authentication and diversity assessments. Zookeys 365 , 49-65.

Ardura, A., Zaiko, A., Martinez, J.L., Samuiloviene, A., Borrell, Y., Garcia-Vazquez, E. 2015. Environmental DNA evidence of transfer of North Sea molluscs across tropical waters through ballast water. J. Molluscan Stud., http://dx.doi.org/10. 1093/mollus/eyv022.

Baker, C., 2014, Pierce Lab, Department of Organismic and Evolutionary Biology, Harvard University (<ccmbaker@fas.harvard.edu>).

Betancur-R, R., Broughton, R.E., Wiley, E.O., Carpenter, K., López, J.A., Li, C. et al., 2013, The Tree of Life and a New Classification of Bony Fishes, PLoS Currents Tree of Life.Apr 18. Edition 1, <10.1371/currents.tol. 53ba26640df0ccaee75bb165c8c26288>.

Bott, N.J., Ophel-Keller, K.M., Sierp, M.T., Herdina, Rowling, K.P., McKay, A.C., et al., 2010. Toward routine, DNA-based detection methods for marine pests. Biotechnol. Adv. 28, 706-714.

Bottero, M.T., Dalmasso, A., 2011. Animal species identification in food products: evolution biomolecular methods. Vet. J. 190, 34-38.

Caporaso, J.G., Kuczynski, J., Stombaugh, J., Bittinger, K., Bushman, F.D., Costello, E.K., et al., 2010. QIIME allows analysis of high-throughput community sequencing data. Nat. Methods. 7, 335-336.

Cheng, C.H., Kawasaki, T., Chiang, K.P., Ho, C.H., 2013. Alternative assessment methods applied to the hairtail (Trichiurus lepturus) stock in the Aru Sea as an example. J. Mar. Sci. Technol. 21, 223-229.

Cheung, W.W.L., Pitcher, T.J., Pauly, D., 2005. A fuzzy logic expert system to estimate intrinsic extinction vulnerabilities of marine fishes to fishing. Biol. Conserv. 124, 97-111.

Clarke, L.J., Soubrier, J., Weyrich, L.S., Cooper, A., 2014. Environmental metabarcodes for insects: in silico PCR reveals potential for taxonomic bias. Mol. Ecol. Resour. 14, 1160-1170.

Collins, R.A., Armstrong, K.F., Meier, R., Yi, Y., Brown, S.D.J., Cruickshank, R.H., Keeling, S., et al., 2012. Barcoding and border biosecurity: identifying cyprinid fishes in the aquarium trade. PLoS One 7 (1), e28381, http://dx.doi.org/10. 1371/journal.pone.0028381.

De Battisti, C., Marciano, S., Magnabosco, C., Busato, S., Arcangeli, G., Cattoli, G., 2014. Pyrosequencing as a tool for rapid fish species identification and commercial fraud detection. J. Agric. Food. Chem. 62, 198-205.

Deagle, B.E., Jarman, S.N., Coissac, E., Pompanon, F., Taberlet, P., 2014. DNA metabarcoding and the cytochrome c oxidase subunit I marker: not a perfect match. Biol. Lett. 10, 20140562.
Diana, J.S., 2009. Aquaculture production and biodiversity conservation. BioScience $59,27-38$

Doosti, A., Abbasi, P., Ghorbani-Dalini, S., 2011. Fraud identification in fishmeal using polymerase chain reaction (PCR). Afr. J. Biotechnol. 10, 12762-12765.

El-Halfawy, M.M., Amin, A.M., Ramadan, A.M., 2007. Growth and reproduction of female brushtooth lizard fish Sauridaundosquamis (Richardson) from the Gulf of Suez, Egypt. J. Fish. Aqua. Sci. 24, 143-148.

El-Sayed, A.F.M., 2007. Analysis of feeds and fertilizers for sustainable aquaculture development in Egypt, In: Hasan, M. R., Hecht, T., De Silva, S.S., Tacon, A.G.J., Study and analysis of feeds and fertilizers for sustainable aquaculture development, FAO Fisheries Technical Paper No. 497, Rome, pp. 401-422.

El-Sayed, A.F.M., 2014. Value Chain Analysis of the Egyptian Aquaculture Feed Industry Project Report: 2014-22. WorldFish, Penang, Malaysia.

FAO, 2007, The State of World Fisheries and Aquaculture, Rome.

FAO, 2011. Review of the State of World Marine Fishery Resources. FAO Fisheries and Aquaculture Technical Paper No. 569. FAO, Rome, pp. 334.

FAO, 2012. The state of world fisheries and aquaculture 2012, Rome.

FAO, 2013. FAOSTAT (http://faostat.fao.org/site/339/default.aspx).

FAO, 2014. The State of World Fisheries and Aquaculture 2014. Rome, 223 pp.

Feidi, I.H., 2003. Impact of International Fish Trade on Food Security in Egypt. Report of the Expert Consultation on International Fish Trade and Food Security, Morocco, FAO Fisheries Report. No. 708. Rome, FAO.

Ficetola, G.F., Miaud, C., Pompanon, F., Taberlet, P., 2008. Species detection using environmental DNA from water samples. Biol. Lett. 4, 423-425.

Ficetola, G.F., Pansu, J., Bonin, A., Coissac, E., Giguet-Covex, C.H., De Barba, M., et al., 2015. Replication levels, false presences and the estimation of the presence/absence from eDNA metabarcoding data. Mol. Ecol. Resour., http:// dx.doi.org/10.1111/1755-0998.12338.

Frey, K.G., Herrera-Galeano, J.E., Redden, C.L., Luu, T.V., Servetas, S.L., Mateczun, A.J., et al., 2014. Comparison of three next-generation sequencing platforms for metagenomic sequencing and identification of pathogens in blood. BMC Genom. 15, 96.

GAFRD (General Authority for Fisheries Resources Development), 2013. Fisheries Statistics Year Book. GAFRD, Cairo.

Goldberg, C.S., Strickler, K.M., Pilliodr, D.S., 2015. Moving environmental DNA methods from concept to practice for monitoring aquatic macroorganisms. Biol. Conserv. 183, 1-3.

Gomez, D.K., Mori, K.I., Okinaka, Y., Nakai, T., Park, S.C., 2010. Trash fish can be a source of betanodaviruses for cultured marine fish. Aquaculture 302, $158-163$.

Goulding, I., Kamel, M., 2013. Institutional, Policy and Regulatory Framework for Sustainable Development of the Egyptian Aquaculture Sector. Project Report: 2013-39. WorldFish, Penang, Malaysia.

Hadziavdic, K., Lekang, K., Lanzen, A., Jonassen, I., Thompson, E.M., Troedsson, C., 2014. Characterization of the $18 \mathrm{~S}$ rRNA gene for designing universal eukaryote specific primers. PLoS One 9 (2), e87624, http://dx.doi.org/10.1371/journal. pone.0087624.

Hajibabaei, M., Smith, M.A., Janzen, D.H., Rodriguez, J.J., Whitfield, J.B., Hebert, P.D.N., 2006. A minimalist barcode can identify a specimen whose DNA is degraded. Mol. Ecol. Notes 6, 959-964.

Hargreaves, J.A., 1998. Nitrogen biogeochemistry of aquaculture ponds. Aquaculture 166, 181-212.

Hasan, M.R., Halwart, M., 2009. Fish as Feed Inputs for Aquaculture: Practices, Sustainability and Implications. FAO Fisheries and Aquaculture Technical Paper. No. 518. FAO, Rome.

Hebert, P.D.N., Cywinska, A., Ball, S.L., DeWaard, J.R., 2003. Biological identifications through DNA barcodes. Proc. R. Soc. Lond. B. Biol. Sci. 270, 313-321.

Hellberg, R.S., Morrisey, M.T., 2011. Advances in DNA-based techniques for the detection of seafood species substitution on the commercial market. J. Lab. Autom. 16, 308-321.

Herdson, D., Priede, I., 2010. Clupeaharengus. The IUCN Red List of Threatened Species. Version 2014.3. <www.iucnredlist.org>. Downloaded on (14.03.15.)

Huntington, T.C., Hasan, M.R., 2009. Fish as feed inputs for aquaculture practices, sustainability and implications: a global synthesis, In: Hasan, M.R., Halwart, M., Fish as feed inputs for aquaculture: practices, sustainability and implications, FAO Fisheries and Aquaculture Technical Paper No. 518, Rome, pp. 1-61.

Jackson, A., 2012. Fishmeal and fish oil and its role in sustainable aquaculture. Int Aquafeed 15, 18-21.

Jianguo, D.U., Zhenbin, L.U., Shengyun, Y., Mingru, C., 2011. Studies on ecological characteristics variation and population dynamics of four lizard fishes in the southern Taiwan Straits. Acta Oceanologica Sin. 30, 72-81.

Jin-qing, Y.E., Zhao-li, X.U., Jia-jie, C., Wei, K., 2012. Resources status analysis of large yellow croaker in Guanjinyang using von Bertalanffy growth equation and fishing mortality parameters. J. Fish. China, http://dx.doi.org/10.3724/SP.J. $; 1 ; 1231.2012 .27640$.

Krcmar, P., Rencova, E., 2005. Quantitative detection of species-specific DNA in feedstuffs and fish meals. J. Food Prot. 68, 1217-1221.

Kwong, S., Srivathsan, A., Meier, R., 2012. An update on DNA barcoding: low species coverage and numerous unidentified sequences. Cladistics 28 , 639-644, http://dx.doi.org/10.1111/j.1096-0031.2012.00408.x.

Mahmoud, H.H., El Haweet, A.A.K., Dimech, M., 2014. Stock assessment of the alien species Brushtooth lizard fish, Saurida undosquamis (Richardson, 1848) in the Egyptian Mediterranean coast. Egypt. J. Aqua. Res. 40, 434-450.

Martín, I., García, T., Rojas, M., Pegels, N., Pavón, M.A., Hernández, et al., 2010. Real-time polymerase chain reaction detection of fishmeal in feedstuffs. J. AOAC Int. 93, 1768-1777. 
Meriem, S.B., Al-Marzouqi, A., Al-Mamry, J., Al-Mazroui, A., 2011. Stock assessment and potential management of Trichiurus lepturus fisheries in the Arabian Sea, Oman. J. Fish. Aqua. Sci. 6, 212-224.

Meusnier, I., Singer, G.A.C., Landry, J.F., Hickey, D.A., Hebert, P.D.N., Hajibabaei, M 2008. A universal DNA mini-barcode for biodiversity analysis. BMC Genom. 9 214.

Miles, R.D., Chapman, F.A., 2006. The Benefits of Fish Mealin Aquaculture Diets. Florida Cooperative Extension Service, IFAS, University of Florida. EDIS FA 122, (http://edis.ifas.ufl.edu/pdffiles/FA/FA12200.pdf). Last accessed (01.09.14.).

Morozova, O., Marra, M.A., 2008. Applications of next-generation sequencing technologies in functional genomics. Genomics 92, 255-264.

Olvera-Novoa, M.A., Domínguez-Cen, L.J., Olivera-Castillo, L., Martínez-Palacio, C.A., 1998. Effect of the use of the microalga Spirulina maxima as fish meal replacement in diets for tilapia, Oreochromis mossambicus (Peters), fry. Aquacult. Res. 29, 709-715.

Ong, S.B., Zuraini, M.I., Jurin, W.G., Cheah, Y.K., Tunung, R., Chai, L.C., et al., 2007. Meat molecular detection: sensitivity of polymerase chain reaction-restriction fragment length polymorphism in species differentiation of meat from animal origin. ASEAN Food J. 14, 51-59.

Pawlowski, J., Esling, P., Lejzerowicz, F., Cedhagen, T., Wilding, T.A., 2014 Environmental monitoring through rotest next-generation sequencing metabarcoding: assessing the impact of fish farming on benthic foraminifera communities. Mol. Ecol. Res. 14, 1129-1140.

Pochon, X., Bott, N.J., Smith, K.F., Wood, S.A., 2013. Evaluating detection limits of next-generation sequencing for the surveillance and monitoring of international marine pests. PLoS One 8, 73935, http://dx.doi.org/10.1371/ journal.pone.0073935.

Quail, M.A., Smith, M., Coupland, P., Otto, T.D., Harris, S.R., Connor, T.R., et al., 2012. A tale of three next generation sequencing platforms: comparison of Ion Torrent, Pacific Biosciences and Illumina MiSeq sequencers. BMC Genom. 13, 341.

Rees, H.C., Maddison, B.C., Middleditch, D.J., Patmore, J.R.M., Gough, K.C., 2014. Review: the detection of aquatic animal species using environmental DNA-a review of eDNA as a survey tool in ecology. J. Appl. Ecol. 51, 1450-1459.

Reuben, S., Vijayakumaran, K., Achayya, P., Prabhakar, R.V.D., 1997. Biology and exploitation of Trichiurus lepturus Linnaeus from Visakhapatnam waters. Indian J. Fish. 44, 101-110.

Roest Crollius, H., Weissenbach, J., 2005. Fish genomics and biology. Genome Res 15, 1675-1682.

Ronaghi, M., 2001. Pyrosequencing sheds light on DNA sequencing. Genome Res $11,3-11$.

Salipante, S.J., Kawashima, T., Rosenthal, C., Hoogestraat, D.R., Cummings, L.A. Sengupta, D.J., et al., 2014. Performance comparison of illumina and ion torrent next-generation sequencing platforms for $16 \mathrm{~S}$ rRNA-based bacterial community profiling. Appl. Environ. Microbiol. 80, 7583-7591.
Schmieder, R., Edwards, R., 2011. Fast identification and removal of sequence contamination from genomic and metagenomic datasets. PLoS One 6, 17288

Taberlet, P., Coissac, E., Hajibabaei, M., Rieseberg, L.H., 2012. Environmental DNA. Mol. Ecol. 21, 1789-1793.

Tacon, A.G.J., 2004. Use of fish meal and fish oil in aquaculture: a global perspective. Aqua. Res. Cult. Dev. 1, 3-14.

Tacon, A.G.J., Hasan, M.R., Subasinghe, R.P., 2006. Use of Fishery Resources as Feed Inputs for Aquaculture Development: Trends and Policy Implications. FAO Fisheries Circular No. 1018. FAO, Rome, pp. 99.

Tacon, A.G.J., Metian, M., 2008. Global overview on the use of fish meal and fish oil in industrially compounded aquafeeds: trends and future prospects. Aquaculture 285, 146-158.

Tamura, K., Stecher, G., Peterson, D., Filipski, A., Kumar, S., 2013. MEGA6: molecular evolutionary genetics analysis version 6.0. Mol. Biol. Evol. 30, 2725-2729.

Thompson, K.R., Velasquez, A., Patterson, J.T., Metts, L.S., Webster, C.D., Brady, Y.J., et al., 2012. Evaluation of plant and animal protein sources as partial or total replacement of fish meal in diets for Nile tilapia fry and juvenile stages. North Am. J. Aquac. 74, 365-375.

Thomsen, P.F., Kielgast, J., Iversen, L.L., Moller, P.R., Rasmussen, M., Willerslev, E. 2012. Detection of a diverse marine fish fauna using environmental DNA fromseawater samples. PLoS One 7, e41732.

Trosvik, K.A., Webster, C.D., Thompson, K.R., Metts, L.A., Gannam, A., Twibell, R. 2013. Effects on growth performance and body composition in Nile tilapia, Oreochromis niloticus, fry fed organic diets containing yeast extract and soyabean meal as a total replacement of fish meal without amino acid supplementation. Biol. Agric. Hortic. 29, 173-185.

Vidthayanon, C., Hogan, Z., 2013. Pangasianodon hypophthalmus, The IUCN Red List of Threatened Species, Version 2014.3. <www.iucnredlist.org>, Downloaded on 02 February 2015.

Wilcox, T.M., McKelvey, K.S., Young, M.K., Jane, S.F., Lowe, W.H., Whiteley, A.R. et al., 2013. Robust detection of rare species using environmental DNA: the importance of primer specificity. PLoS One 8, 59520.

Zaiko, A., Martinez, J.L., Schmidt-Petersen, J., Ribicic, D., Samuiloviene, A Garcia-Vazquez, E., 2015a. Metabarcoding approach for the ballast water surveillance-an advantageous solution or an awkward challenge? Mar. Pollut. Bull. 92, 25-34

Zaiko, A., Martinez, J.L, Ardura, A., Clusa, L, Borrell, YJ., Samuiloviene, A., et al. 2015b. Detecting nuisance species using NGST: methodology shortcomings and possible application in ballast water monitoring. Mar. Environ. Res., http:// dx.doi.org/10.1016/j.marenvres.2015.07.002

Zirong, H., Zuozhi, C., 2005. Stock variation of Sauridatumbil in southwestern continental of Nansha Islands. Trans. Oceanol. Limnol. 3, 50-56. Acero, A. Fricke, R., Murdy, E. 2010. Chelidonichthys kumu. The IUCN Red List of Threatened Species. Version 2014.3. <www.iucnredlist.org>. Downloaded on 06 February 2015 